\title{
Quality or quantity: small-scale patch structure affects patterns of biodiversity in a sublittoral blue mussel community
}

\author{
Maria Koivisto $^{1,2, *}$, Mats Westerbom ${ }^{1,3}$, Anna Arnkil ${ }^{1,2}$ \\ ${ }^{1}$ Tvärminne Zoological Station, Helsinki University, J.A. Palménsväg 260, 10900 Hangö, Finland \\ ${ }^{2}$ Department of Environmental Sciences, Aquatic Sciences, Helsinki University, PB 56, 00014 Helsinki University, Finland \\ ${ }^{3}$ Metsähallitus, Natural Heritage Services, PO Box 94, 01301 Vantaa, Finland
}

\begin{abstract}
It is widely accepted that blue mussel Mytilus edulis L. beds support a high macrofaunal diversity. Nonetheless, sublittoral mussel beds on rocky shores have rarely been examined in a patch context to determine the processes creating and maintaining the diversity and assemblages of organisms occupying them. Whereas the species-area relationship is a well-established theory in ecology, less is known about its effect on faunal compositions in aquatic habitats. Also, the effect of patch shape and relative patch edge are poorly studied within a rocky shore mussel framework. The present study examined the effects of blue mussel patch size, patch shape, and the presence of algae and sand in mussel patches on the composition and diversity of associated macrofaunal communities in sublittoral habitats. In line with the species-area relationship, we found that the total number of taxa increased with patch size up to ca. $500 \mathrm{~cm}^{2}$, thereafter declining. Small patches largely lacked annelid worms and showed a lower diversity of gastropod species. We also found that the diversity was further enhanced by a high biomass of blue mussels, the presence of algae and the weight of interstitial sand. The shape of the patch had no effect on species richness, but affected the species composition. We conclude that structural components of sublittoral blue mussel habitats, such as patch content and shape, greatly affect the diversity and faunal assemblage. This has important implications in conservation biology, since habitats are becoming more fragmented. Our study demonstrates that not only habitat quantity, but also quality has a large impact on species communities in marine ecosystems.
\end{abstract}

KEY WORDS: Species-area relationship ' Patch shape - Edge effect - Ecosystem engineer · Rocky shores · Macrofauna · Baltic Sea

Resale or republication not permitted without written consent of the publisher

\section{INTRODUCTION}

The species-area relationship is considered one of the few 'laws' in ecology (Scheiner 2003), although less thoroughly studied in the marine realm compared to terrestrial systems (Kostylev 1996, Neigel 2003, Kostylev et al. 2005). More recently, habitat quality has also been shown to play an important role in determining species' distribution patterns in fragmented landscapes since area per se is not always a resource. Instead, the resources or the 'habitat quality' found within the areas might be the crucial factor (Gaston \& Matter 2002). Habitat quality, although still badly conceptualized, is usually measured in the form of structural attributes, resources, or direct effects on populations (Mortelliti et al. 2010). In addition, the relative patch edge has been found to influence marine communities, and it has been suggested that changes in the ratio of perimeter length $(P)$ to area $(A), P: A$, and patch shape might affect the number of species able to inhabit a patch (e.g. Bologna \& Heck 2000, Tanner 2003, Jelbart et al. 2006). However, there is very little 
experimental evidence confirming this in marine ecosystems.

Studies in mussel and seagrass beds suggest that patch size affects the number of taxa present (Tsuchiya \& Nishihira 1985, Witman 1985, Bell et al. 2001, Bowden et al. 2001, Norling \& Kautsky 2008). Nonetheless, few studies have clearly distinguished its role in determining the faunal communities, and the relationship can sometimes be non-linear and scale dependent (Kelaher 2003). For example, there might be distinct thresholds after which the influence of habitat structure changes in direction and/or magnitude, or there might be a minimum amount of structure that is required before positive benefits are implemented (Coull \& Wells 1983, Gotceitas \& Colgan 1989). Also, upper thresholds, beyond which increased habitat structure no longer has an effect or even negatively affects the associated fauna, may exist (Fonseca et al. 1996, Kelaher 2003). Not only patch size, but also the architectural complexity (e.g. Kostylev et al. 1997, Commito \& Rusignuolo 2000, Erlandsson et al. 2005), as well as the density and size of the habitat-forming species itself has been shown to influence the diversity and abundance of associated species (Tsuchiya \& Nishihira 1986, Palomo et al. 2007, O'Connor \& Crowe 2007, Koivisto et al. 2011).

On structurally simple substrates, such as bare sand or rocky substrates, blue mussels Mytilus edulis L. aggregate into patches and provide the surrounding habitat with complex physical structures, covering a broad spectrum of mussel size compositions, patch sizes and vast areal coverage. The mussel structures promote the existence of rich faunal communities by providing settling substrate (Dayton 1971, Laihonen \& Furman 1986, Kostylev 1996), food and shelter (Ragnarsson \& Raffaelli 1999) and by modulating the hydrodynamic forces within and above the patches (Kautsky \& Wallentinus 1980), thereby functioning as ecosystem engineers (sensu Jones et al. 1997). It is well known that blue mussels enhance macrofaunal diversity, but we still have limited knowledge about the underlying processes in various systems. Especially sublittoral blue mussel beds on rocky shores have remained largely unstudied in a patch-architecture-related sense, e.g. the interacting effects of patch size, shape, inpatch location and amount of edge are poorly known (however, see Svane \& Setyobudiandi 1996).

In the northern Baltic Sea, blue mussels exist at the margin of their distribution, due to the low salinity, where they uphold rich faunal communities despite their small size and fluctuating coverage (Norling \& Kautsky 2008, Koivisto \& Westerbom 2010). They exhibit natural expansion, fragmentation and contraction due to seasonal growth, die-off, storm events, fluctuating salinity conditions and ice scour (Westerbom et al.
2002). The varying spatial patterns of blue mussels and bare areas, as well as structures associated with mussel beds, e.g. macroalgae, sand and organic sediment, may directly or indirectly affect associated faunal assemblages through a number of mechanisms such as alteration of predator abundance and foraging behavior (e.g. Leber 1985, Main 1987, Irlandi et al. 1995), modifications of water flow (Kautsky \& Wallentinus 1980), accumulation of secondary structure, such as drifting algae (Norkko et al. 2000), and changes in animal behavior. In the present study, we were interested in examining how the mussel bed structure on a within-shore scale influences faunal communities. We tested the effects of (1) patch size, (2) patch shape and (3) 'patch quality' in terms of algal and sand presence in rocky shore mussel patches. We hypothesized that not only patch size, but also patch shape and the presence of sand and algae may influence the associated communities, with supplemental structures having a positive impact on the fauna.

\section{MATERIALS AND METHODS}

Study site and sampled patch types. All field work was carried out at 2 rocky sites in the Hanko-Tvärminne area in the Gulf of Finland $\left(59^{\circ} 48^{\prime} \mathrm{N}, 23^{\circ} 12^{\prime} \mathrm{E}\right)$, northern Baltic Sea during the summer seasons 2008 and 2009. The Spikarna site is a group of small islands and sublittoral reefs with a fragmented distribution of mussel beds interspersed by pockets of sand fields, stones and gravel. Långskärsklack is a large rocky reef area with dense and homogeneous mussel beds. We chose these sites because they contain a structural range of blue mussel beds - from large continuous areas to small patches surrounded by bare rock.

To study how patch size and shape, as well as the presence of algae and sand, influence macrofaunal communities, equal areas $(10 \times 10 \mathrm{~cm})$ from differently structured hard-bottom mussel patches were sampled from the Spikarna site at $5 \mathrm{~m}$ depth $(\mathrm{n}=10)$. Sampling was done in October 2009 using SCUBA. Square patches (sq) with a high $P: A$ ratio and rectangular (rec) patches with both large perimeter and large area were sampled to study the effects of the edge portions and shapes of blue mussel beds in 2 size categories (Small sq, Small rec; Big sq, Big rec). To study how the presence of algae and sand influence communities, squareshaped mussel beds containing sand (Sand) and square-shaped mixed patches of mussels and the red algae Coccothylus truncatus (Algae) were sampled. Finally, to increase the range of patch size, very small (XS) and very large (XL) square-shaped mussel patches were sampled. All patches were sampled from the middle of the patch and taken by scraping off the 
total contents of a $10 \times 10 \mathrm{~cm}$ quadrate frame into an attached fabric sampling bag (see Westerbom et al. 2002). After the sample was taken, the shapes of the original patches were redrawn on a transparent plastic film and the perimeter and area were calculated. The sizes of the smallest patches were calculated from photographs, taken prior to sampling. A mean shape index (MSI) was calculated for each patch using the formula presented in Saura \& Carballal (2004). The MSI is attained by calculating the sum of each patch perimeter divided by the square root of the patch area. It attains a minimum value of 1 when the patch is fully circular and increases with no theoretical upper limit as the shape becomes more irregular and elongated (Saura \& Carballal 2004). Table 1 summarizes the different habitat characteristics in the sampled blue mussel patches.

Experimental patches. To further test the effects of patch shape on macrofaunal communities, we constructed mussel patches into large homogeneous mussel beds at the Långskärsklack site. In May 2008, blue mussel patches of 4 different shapes were created in 10 blocks, each spanning approximately $7 \times 2.5 \mathrm{~m}$. Blocks were arranged in a row over a transect with approximately $10 \mathrm{~m}$ between blocks at $5 \mathrm{~m}$ depth. These blocks of patches were created in areas with close to full coverage of mussels, thus producing fragmentation in terms of patches in an unfragmented seascape. In addition to patch shape effects, we were interested in elucidating how the assemblage structure changes when a previous homogeneous area is turned into a fragmented area consisting of patches. Moulds were placed in large homogeneous mussel beds, and the surrounding was removed by scraping and brushing so that all mussels, barnacles and algae outside the moulds were removed from the block. Patch designs used were (1) a large square $(0.5 \times 0.5 \mathrm{~m})$ and (2) a large rectangle with the same area and perimeter $(0.4 \times 0.625 \mathrm{~m})$. Additionally, to separate the possible effects of area and perimeter, (3) a rectangular patch with the same perimeter but different area was created $(0.2 \times 0.8 \mathrm{~m})$. Finally, to test for differences in the inpatch location, (4) another square-shaped patch $(0.5 \times$ $0.5 \mathrm{~m}$ ) was created and sampled from the edge; Fig. 1). Patch types were randomly distributed to the block, and distances between patches and all edges in the block were ca. $1 \mathrm{~m}$. The patches were left open for colonization during $5 \mathrm{mo}$, after which they were sampled with a $20 \times 20 \mathrm{~cm}$ metal frame with an attached sampling bag. The fauna in the patches was also compared with unmanipulated, continuous-control mussel beds from the same area, sampled outside each block ( $\mathrm{n}=10)$.

In addition, smaller square $(20 \times 20 \mathrm{~cm})$ and rectangular $(10 \times 40 \mathrm{~cm})$ blue mussel patches were created in the Spikarna area in May 2008. Patches were created by placing transplanted blue mussels into plastic-bottom and roofless frames (mesh size: $0.5 \mathrm{~cm}$ ) attached to the bottom by wedges (see setup in Koivisto \& Westerbom 2010). Before transplantation, all associated invertebrates were removed from the mussels except for Balanus improvisus Darwin and Electra crustulenta (Pallas), which grow as epifauna on the shells. Frames were removed 1 mo after attachment, leaving behind

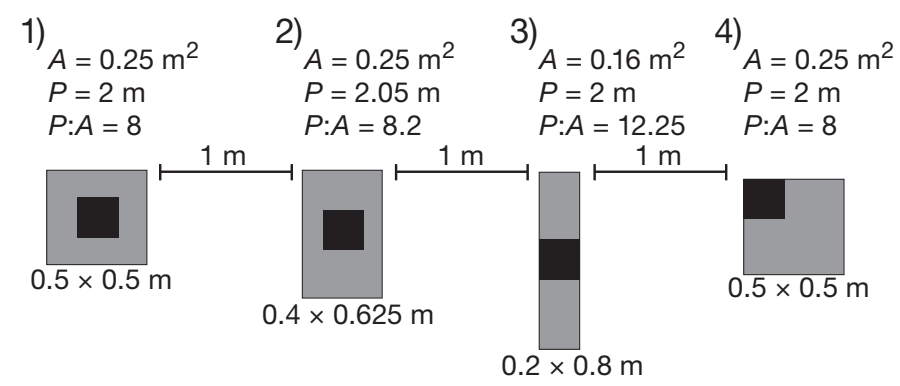

Fig. 1. Schematic renderings of 4 experimental patch designs. Replicates of all treatments $(n=10)$ were placed in 10 blocks over a transect. Black parts mark the sampling site in each patch. $A$ : area; $P$ : perimeter

Table 1. Patch characteristics of the sampled blue mussel Mytilus edulis beds (mean $\pm \mathrm{SE} ; \mathrm{n}=10$ ). Patch abbreviations - XS: very small; sq: square; rec: rectangle; Algae: small square containing algae; Sand: small square containing sand; XL: very large. Other abbreviations-DW: dry weight; AFDW: ash-free dry weight; $P$ : perimeter; A: area; MSI: mean shape index

\begin{tabular}{|lccccccccc|}
\hline Patch type & $\begin{array}{c}\text { Biomass } \\
(\mathrm{g} \mathrm{DW})\end{array}$ & $\begin{array}{c}\text { Mussel density } \\
\left(\text { ind. } \mathrm{cm}^{-2}\right)\end{array}$ & $\begin{array}{c}\text { Perimeter } \\
(\mathrm{cm})\end{array}$ & $\begin{array}{c}\text { Area } \\
\left(\mathrm{cm}^{2}\right)\end{array}$ & $\begin{array}{c}\text { Size range } \\
\left(\mathrm{cm}^{2}\right)\end{array}$ & $P:$ A ratio & MSI & $\begin{array}{c}\text { Sand } \\
(\mathrm{g} \text { AFDW })\end{array}$ & $\begin{array}{c}\text { Algae } \\
(\mathrm{g} \mathrm{DW})\end{array}$ \\
\hline XS & $5 \pm 0.8$ & $3.4 \pm 0.3$ & $29 \pm 1$ & $40 \pm 3$ & $30-100$ & $0.77 \pm 0.05$ & $26 \pm 1$ & $1.5 \pm 0.3$ & 0 \\
Small sq & $73 \pm 9$ & $3.0 \pm 0.3$ & $63 \pm 4$ & $204 \pm 20$ & $150-300$ & $0.32 \pm 0.01$ & $56 \pm 3$ & $8.0 \pm 2.6$ & $0.2 \pm 0.1$ \\
Small rec & $24 \pm 3$ & $1.4 \pm 0.1$ & $62 \pm 2$ & $158 \pm 8$ & $150-300$ & $0.39 \pm 0.01$ & $53 \pm 1$ & $2.4 \pm 0.7$ & $0.01 \pm 0$ \\
Algae & $90 \pm 16$ & $4.8 \pm 0.3$ & $60 \pm 5$ & $193 \pm 29$ & $150-300$ & $0.34 \pm 0.02$ & $54 \pm 4$ & $4.7 \pm 1.0$ & $1.8 \pm 0$ \\
Sand & $91 \pm 13$ & $3.0 \pm 0.1$ & $87 \pm 10$ & $284 \pm 29$ & $150-300$ & $0.33 \pm 0.05$ & $73 \pm 6$ & $44.1 \pm 9.3$ & $0.1 \pm 0.1$ \\
Big sq & $151 \pm 16$ & $2.6 \pm 0.3$ & $102 \pm 7$ & $471 \pm 46$ & $300-600$ & $0.22 \pm 0.01$ & $89 \pm 5$ & $15.1 \pm 2.0$ & $0.2 \pm 0$ \\
Big rec & $138 \pm 15$ & $2.6 \pm 0.2$ & $113 \pm 7$ & $390 \pm 34$ & $300-600$ & $0.29 \pm 0.02$ & $91 \pm 5$ & $12.5 \pm 2.5$ & $0.1 \pm 0.1$ \\
XL & $235 \pm 29$ & $2.2 \pm 0.2$ & $149 \pm 12$ & $850 \pm 71$ & $600-1000$ & $0.18 \pm 0$ & $126 \pm 8$ & $25.9 \pm 5.1$ & $0.03 \pm 0.01$ \\
\hline
\end{tabular}


only the blue mussels, to minimize cage effects and to ease later sampling. The patches were open for colonization during $5 \mathrm{mo}$, after which the total contents of the patches were sampled using a metal frame corresponding to each of the 2 patch sizes and shapes with an attached sampling bag. Replicate treatments $(\mathrm{n}=$ 15) were randomly assigned to positions and located at least $1 \mathrm{~m}$ apart from each other. The mussel densities and sizes in the patches were equivalent to those found in natural control blue mussel patches of the same area (density, ANOVA: $F_{2,27}=0.99, \mathrm{p}>0.05$; size, Kolmogorov-Smirnov: $\mathrm{p}>0.05$ ).

Processing of samples. After sampling, the fauna was sorted by size through a series of sieves (mesh sizes: $9.5,4,2,1$ and $0.5 \mathrm{~mm}$ ) to ease the counting of all individuals; subsequently the fauna was identified to the lowest taxonomic level possible. The smallest fraction in all samples was analysed using a preparation microscope (Leica S6E). While the barnacles Balanus improvisus were included in the counts from natural samples, they were excluded from the analysis in the experimental patches, since they were already present as epifauna on mussel shells at the beginning of the experiment. The bryozoa Electra crustulenta was also excluded from all analyses. Blue mussel biomass was estimated according to the formula presented by Westerbom et al. (2002). The amount of sand in each sample was measured as ash-free dry weight (AFDW), after combustion of the sand samples at $500^{\circ} \mathrm{C}$ for $4 \mathrm{~h}$. The amount of organic content $(\mathrm{g})$ in the patch was determined as the weight difference between initial sand dry weight (after $48 \mathrm{~h}$ in $60^{\circ} \mathrm{C}$ ) and AFDW after combustion. Also, the algae present (Coccothylus truncatus, small amounts of trapped filamentous algae) were dried for $48 \mathrm{~h}$ in $60^{\circ} \mathrm{C}$ and weighed to test for correlations with diversity variables (species richness, abundance and individual taxa), since they might affect the fauna.

Data analyses of natural patches. To assess how species diversity, abundance and individual taxa differ in the sampled patch types, 1-way ANOVA was used. All data were log-transformed before analysis to meet assumptions for parametric testing. Hydrobia spp. were left out of the analysis when comparing the abundance of gastropods, since they strongly dominated the gastropod fauna. Instead, they were tested for separately. To find the best explanatory variables for differences in diversity (species richness, abundance, individual taxa), we performed a multiple linear regression (forward stepwise) with faunal species richness, abundance and individual taxa as dependent variables as a function of patch area, perimeter, $P: A$ ratio, MSI, blue mussel biomass, the amount of organic content ( $g$ ) and the amount of sand (g AFDW). Density was left out of the analysis since it showed collinearity with biomass. There was no problem with multicollinearity between other variables (tolerance $>0.80$, condition index $<$ 7.00). To reduce the risk of inflating Type I errors in multiple regressions, we reduced $\alpha$ to 0.01 for rejecting the null hypothesis (see Grafen \& Hails 2002). Algal weight $(g)$ was also left out of the analyses, since it failed to meet assumptions for parametric testing. Instead, the correlation between algal weight and the above-mentioned diversity variables was tested with a Spearman rank test.

To test whether the species composition in the different natural mussel structures differed, a 1-way fixedfactor, distance-based permutational multivariate analysis of variance (PERMANOVA) was performed with 4999 random permutations of appropriate units with patch type as a fixed factor (Anderson 2001). Analyses were carried out on Bray-Curtis dissimilarities on square-root-transformed data. The data were further investigated using appropriate pairwise comparisons among patch types. Since pairwise comparisons were highly significant, a canonical analysis of principal coordinates (CAP; Anderson \& Willis 2003) was performed to visually compare the assemblages associated with the different patches, and individual taxa with strong correlations with the ordination axes $(\geq 0.3)$ were plotted as arrows in a biplot (Anderson \& Willis 2003).

Data analyses of experimental patches. To study differences in diversity indices (species richness, abundance and individual taxa) in the big experimental blue mussel patches and the natural, continuous mussel beds $(\mathrm{n}=10)$ from the same area, a 1-way ANOVA with patch type as a factor was used. Prior to analysis, KolmogorovSmirnov's and Levene's tests were used to test whether data fulfilled assumptions for parametric testing. If necessary, data were log transformed to fulfill these assumptions. Since area was found to highly affect the fauna in the natural patches, we chose not to include the rectangles with the smaller area in the analysis (Fig. 1; Type 3 patches). The square patches sampled from the edge were also excluded from the ANOVA, but were compared with the other square patches with an independent-samples $t$-test to test if the in-patch location affects the fauna. To examine differences in species assemblages, a 1-way PERMANOVA with patch type as a fixed factor was performed on Bray-Curtis dissimilarities on square-root-transformed data. The overall patterns were visualized with a CAP plot, and species with strong correlations with the axes were plotted as arrows in the biplot $(\geq 0.3)$.

Differences in diversity in the small transplant patches $(20 \times 20 \mathrm{~cm}$ and $10 \times 40 \mathrm{~cm})$ were tested for using an independent-samples $t$-test. All ANOVAs were followed by an a posteriori Student-NewmanKeuls (SNK) test to identify means that differed significantly at $\alpha=0.05$. All tests were performed with SPSS 16.0. The small experimental patches were visualized 
with a non-metric multidimensional scaling plot, and species responsible for differences were investigated using the similarity percentage (SIMPER) procedure, since we only had 2 different treatments $(\mathrm{N}=30)$. All analyses were carried out with the Primer 6 package with the PERMANOVA+ add-on.

\section{RESULTS}

\section{Effects of patch size, structure and shape in natural samples}

Patch size of Mytilus edulis beds significantly influenced species richness and the abundance of Amphipoda, Isopoda, Polychaeta, Platyhelminthes, Nemertea, Bivalvia and Gastropoda. All small patch types
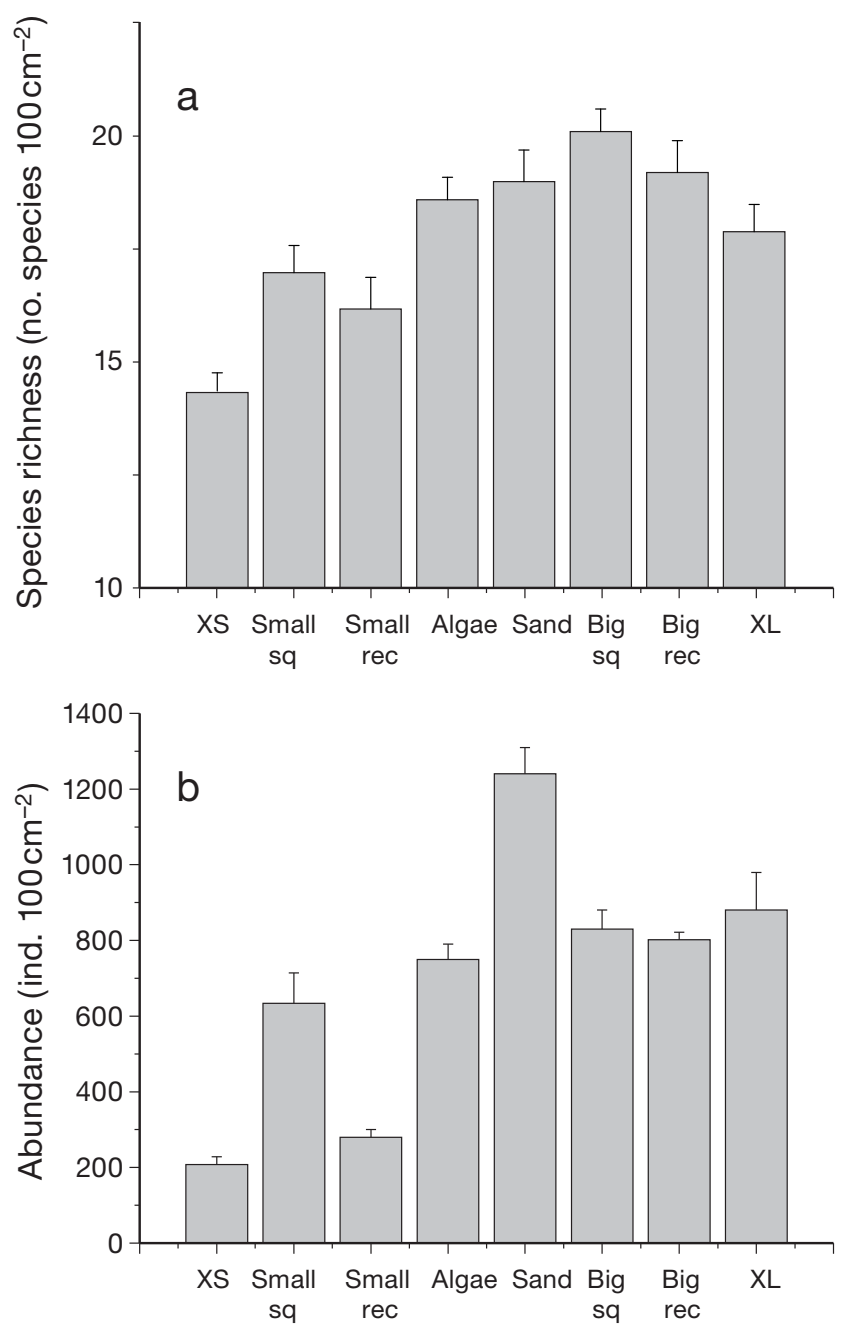

Fig. 2. (a) Total number of species and (b) abundance of individuals in the natural Mytilus edulis beds of different patch structures (average $\pm S E ; n=10$ ). See Table 1 for patch abbreviations and descriptions
(XS, Small sq, Small rec) differed significantly from bigger patches with regard to species richness (SNK, $\mathrm{p} \leq 0.05$; Fig. 2a). Abundance (ind. $\mathrm{cm}^{-2}$ ) was highest in the sandy patches compared to all other patch types, whereas it was significantly the lowest in the very small (XS) and the small rectangular patches (Small rec) (Fig. 2b). Patch size had a positive impact on species richness up to ca. $500 \mathrm{~cm}^{2}$ patch area, thereafter dampening off and even showing a negative trend (Fig. 3).

The stepwise forward linear regression identified overall mussel patch biomass, sand weight and patch area as the best explanatory variables for species richness, together explaining $44 \%$ of the variance (adjusted $\mathrm{R}^{2}=0.44, \mathrm{p} \leq 0.001$ ). The best predictors for faunal abundance were, likewise, mussel biomass, sand weight and patch area, together accounting for $83 \%$ of the variance (adjusted $R^{2}=0.83, p \leq 0.001$ ). The best predictor for the abundance of gastropods, excluding Hydrobia spp., and amphipods was mussel biomass, whereas the amount of organic content was the best predictor for the abundance of isopods, polychaetes, nemerteans, flatworms, bivalves and Hydrobia spp. Algal weight correlated positively, but weakly, with both species richness and abundance (Spearman's $\mathrm{r}_{\mathrm{S}}=$ 0.35 and 0.41 , respectively, $\mathrm{p} \leq 0.001$ ).

Amphipods were most abundant in the algal patches, whereas isopods and nemerteans were most numerous in both algal and sandy patches. Bivalves, other than Mytilus edulis, were most abundant in the sandy patches and gastropods in the small square-shaped (Small sq) and algal patches. The number of flatworms was smallest in the very small patches (XS) and the big squareshaped (Big sq) patches. Polychaetes were significantly more abundant in sandy patches than in other patches

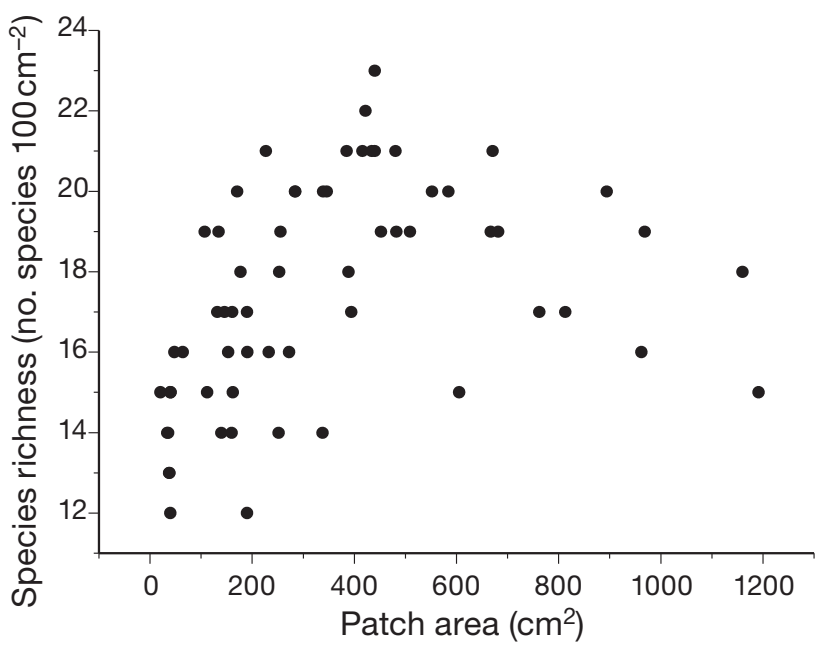

Fig. 3. Relationship between species richness and patch area in natural Mytilus edulis beds. Patches with algae and sand are excluded. $\mathrm{N}=60$ 

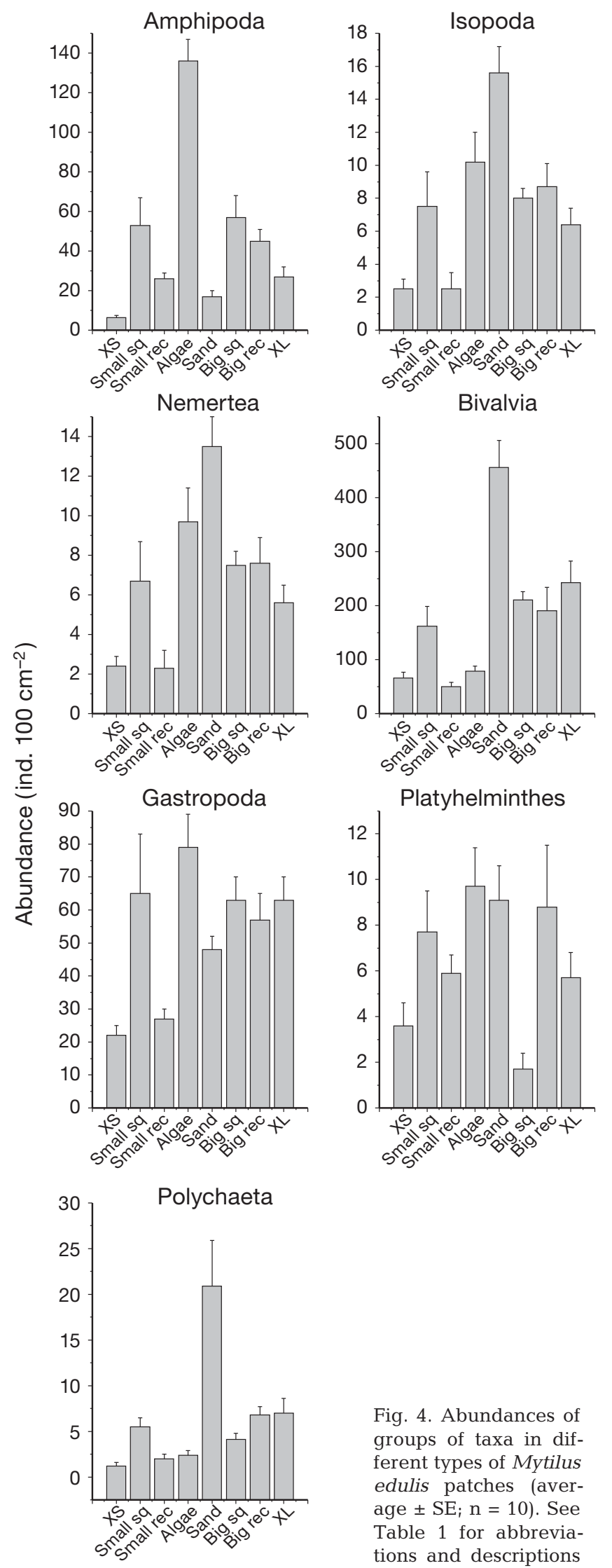

(SNK, $\mathrm{p} \leq 0.05$; Fig. 4). Significant differences were detected in faunal composition between all patch types, except between big rectanglular patches and very large patches (PERMANOVA, pseudo- $F_{7,72}=3.96$, $\mathrm{p}<0.01$ for all pairs; Fig. 5a). The largest differences were found between algal vs. sandy patches and the very small (XS) patches vs. algal, sandy and big square-shaped (Big sq) patches. Isopods, cirripeds, some gastropod species and amphipods were associated with the algal patches, whereas polychaetes and clams were more tightly linked to the sandy patches (Fig. 5b).

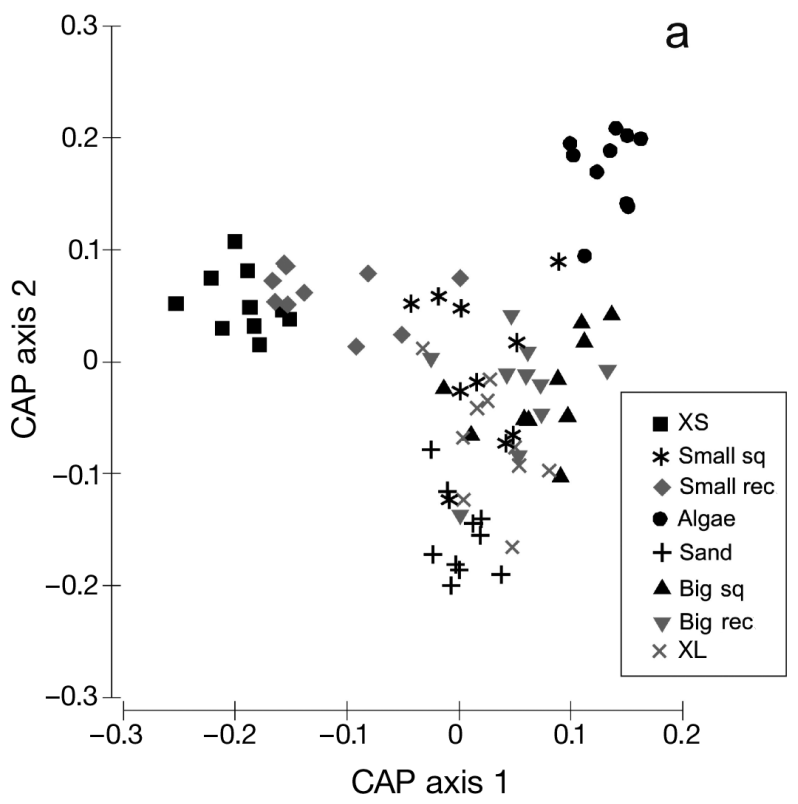

b

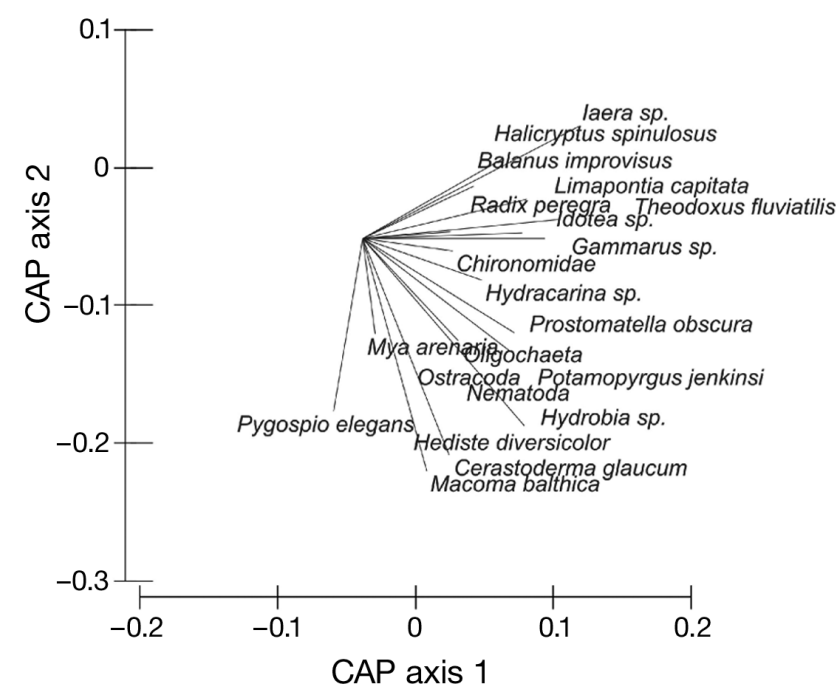

Fig. 4. Abundances of ferent types of Mytilus edulis patches (average $\pm \mathrm{SE}_{;} \mathrm{n}=10$ ). See Table 1 for abbreviations and descriptions

Fig. 5. Canonical analysis of principal coordinates (CAP) plot from the natural Mytilus edulis beds showing (a) canonical axes that best discriminate assemblages in the different mussel patch types and (b) correlations of individual taxa with the canonical axes 


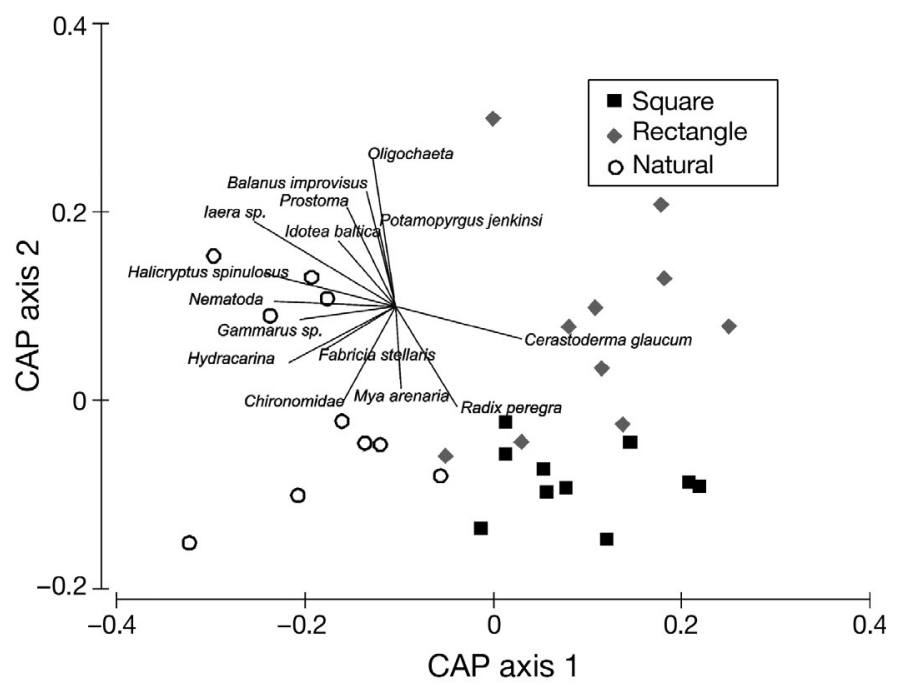

Fig. 6. Canonical analysis of principal coordinates (CAP) plot from the experimental Mytilus edulis blocks and natural, continuous $M$. edulis patches, and correlations of individual taxa with the axes

\section{Effects of patch shape and in-patch location in experimental patches}

There were no differences in species richness or abundance in the large experimental mussel patches of differing shapes. However, when compared with the natural, undisturbed patches from the same area, there were significantly more isopods in the natural beds compared to both manipulated patches, and there were significantly fewer oligochaetes and nematodes in the square-shaped patches (ANOVA: $F_{2,27}=4.83$, $\mathrm{p} \leq 0.05 ; F_{2,27}=3.01, \mathrm{p} \leq 0.05 ;$ and $F_{2,27}=4.01, \mathrm{p} \leq 0.05$; respectively). Species assemblages differed between the natural beds and the square patches (PERMANOVA: pseudo- $\left.F_{2,27}=1.69, \mathrm{p}<0.05\right)$, whereas there were no differences between the differently shaped patches. The multitude of species, except for the clam Cerastoderma glaucum, was more associated with the natural beds, as revealed by the correlations in the CAP plot (Fig. 6). There were also significantly more species in the squares sampled from the core compared to squares sampled from the edge $(18.6 \pm 0.5 \mathrm{vs}$. $16.6 \pm 0.7$ species; $t=2.15, \mathrm{p}<0.05$ )

In the smaller transplant patches, there were more clams in the rectangular patches and more gastropods (both excluding and including Hydrobia spp.) in the square patches, indicating that the amount of edge might influence the colonization of patches and that this varies among taxa $(t=-2.2, \mathrm{p} \leq 0.05 ; t=2.17, \mathrm{p} \leq$ 0.05 ; and $t=2.14, \mathrm{p} \leq 0.05$; respectively). Likewise, assemblages associated with the rectangular and square shapes differed significantly from one another (PERMANOVA: pseudo- $F_{1,29}=3.96, \mathrm{p}<0.01$; Fig. 7).

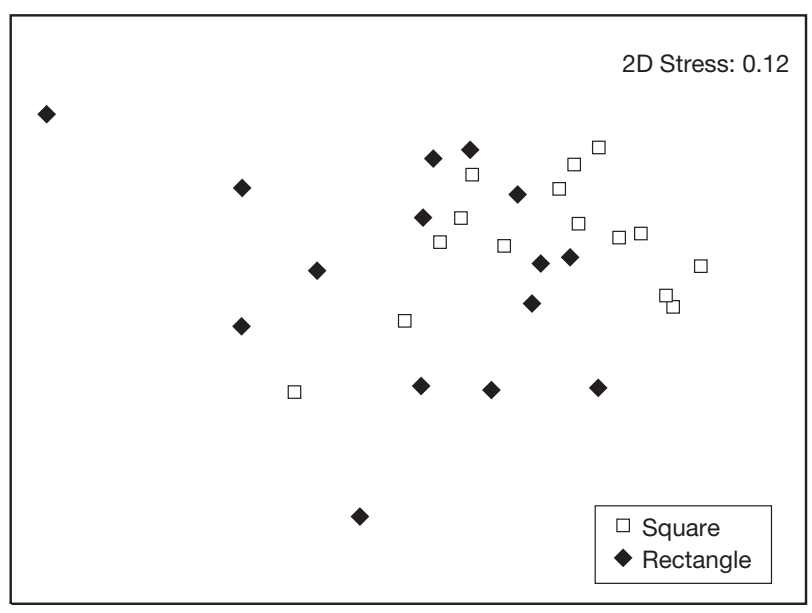

Fig. 7. Non-metric multidimensional scaling plot showing the faunal assemblages associated with the small experimental Mytilus edulis patches of differing shapes. Analysis based on Bray-Curtis dissimilarities on square-root-transformed data

Differences were caused by gastropods (Hydrobia spp., Limapontia capitata), clams (Macoma balthica, Cerastoderma glaucum), amphipods (Gammarus sp.) and isopods (Iaera sp.), as revealed by the SIMPER procedure. There were more gastropods and amphipods in the square patches compared to rectangles, while clams and isopods were more abundant in the rectangular patches compared to squares.

\section{DISCUSSION}

Consistent with the species-area relationship, the present study shows an increase in the number of macrofaunal species in blue mussel patches up to a patch size of ca. $500 \mathrm{~cm}^{2}$, thereafter dampening off. In addition to size, the study shows that other patch qualities have a large impact on faunal diversity and abundance. Especially mussel biomass, the amount of sand and algae, as well as organic content shape species assemblages. Furthermore, the shape and amount of edge influence the prevalence of individual taxa, such as clams, which benefit from elongated patches. Our data therefore confirm both a positive species-area relationship and a taxon-specific edge effect in blue mussel beds. Differences were also found at the species level between the manipulated mussel patches and the continuous mussel beds, showing that fragmentation in continuous mussel landscapes may alter the species composition.

The positive relationship between island area and number of species is one of the most persistent theories in landscape ecology (MacArthur \& Wilson 1967). However, the mechanisms underlying this causal rela- 
tionship are somewhat debated, and its validity has been questioned for marine ecosystems (Anderson 1998). Three general models have been proposed to explain the ecological processes for the species-area relationship. First, the 'random placement hypothesis' (Arrhenius 1921, Coleman 1981) predicts that larger areas generate a higher abundance of organisms and therefore increase the number of species as a random process. According to this model, equal areas sampled, regardless of the size of the patch, should result in the same average number of species. This was not the case in the present study, where clear differences were seen in the different patch types. An alternative explanation is the 'habitat diversity hypothesis', which postulates that the number of species is greater in larger areas because more microhabitats or niches are available (Connor \& McCoy 1979). A third hypothesis explaining the species-area relationship is the equilibrium theory of island biogeography, which predicts that the number of species is lower on smaller 'islands' because the immigration rates will be lower and the extinction rates will be greater compared to larger islands (MacArthur \& Wilson 1967). In accordance with Kostylev et al. (2005), the present study supports the second hypothesis, since many species that require specific resources, such as soft sediment or microalgal cover, were virtually absent from the small patches (Marenzelleria viridis, Fabricia stellaris, Oligochaeta sp., Limapontia capitata, Radix peregra). These resources are likely to be absent or scarce in small blue mussel patches that are frequently wave-swept. Due to their physical structures, larger blue mussel beds are likely to serve a greater ecological function for associated organisms by creating substrates and refuges and trapping resources, such as sediment and sand (Coco et al. 2006). Diversity variables (species richness, abundance) were also positively related to variables such as mussel biomass, patch area and sand weight, which may be connected to the physical structures of the patch. Especially abundance was almost entirely explained by patch area, biomass and sand weight.

The shape of the patch and the amount of edge in this system were less important and were taxon specific. For instance, in the small transplant patches, clams (Macoma balthica, Cerastoderma glaucum) were most abundant in the high $P: A$ rectangular patches, whereas the opposite was true for Hydrobia spp., which had a higher prevalence in the square-shaped patches. Compact habitat patches can support more species and greater population sizes than elongated patches, as the probability of animals emigrating and being lost from the system is reduced (Diamond \& May 1976, Bevers \& Flather 1999). However, elongated patches can also receive a greater number of immigrants than compact patches, especially if they are ori- ented across the flow of dispersing individuals (Hamazaki 1996). As the majority of clams found in the present study represented recruits of the year, the hypothesis of greater larval encounter for elongated patches is supported. Bivalves have also been found to preferentially settle along the edges of seagrass beds (Bologna \& Heck 2000). The higher prevalence of gastropods in compact habitat patches could be explained by a higher content of organic matter that Hydrobia spp. feeds on (Bick \& Zettler 1994), and the abundance of Hydrobia spp. was, indeed, related to the amount of organic content, as seen in the stepwise linear regression model, where it was recognized as one of the explaining variables. The abundance of gastropods and periwinkles has also been shown to decrease with higher architectural complexity in mussel beds (Kostylev 1996, Kostylev et al. 1997, Koivisto et al. 2011). In-patch location influenced species richness, where higher species richness was associated with the interior parts of patches. The in-patch location has also been found to influence the fauna in seagrass patches, where results have been highly variable for different taxa (for review, see Boström et al. 2006).

The present study clearly underpins the importance of scale in the outcome of experimental studies. Differences in faunal communities were seen between patch shapes in the smaller transplant patches, whereas they were absent in the bigger experimental mussel patches. The species-area relationship was evident in mussel patches up to ca. $500 \mathrm{~cm}^{2}$, but a further increase in patch size had no effect on the species richness, demonstrating that there is a threshold beyond which increased patch size no longer affects the associated species (Fig. 3). For blue mussel communities on soft bottoms, Norling \& Kautsky (2007) found a relationship for faunal and floral diversity of up to only $150 \mathrm{~cm}^{2}$. The spatial scale on which measurements are taken is crucial: based on the group of species, the spatial scale determines the type of structural variable that has to be chosen, as different scales require different appropriate variables. Also, the effect of habitat heterogeneity relative to the structural variable measured may vary depending on the spatial scale (Tews et al. 2004), e.g. being positive on a micro- and meso-scale, but non-significant on a macro-scale.

The present study highlights the importance of small-scale habitat and patch characteristics in determining macrofaunal community structure and diversity in subtidal blue mussel habitats. In our study, the presence of algae benefited many species, such as amphipods and gastropods (Fig. 5b), that are likely to find both food and shelter in the algal stands (Koivisto \& Westerbom 2010). The presence of sand added a new dimension to the blue mussel patches and facilitated soft-bottom species, such as polychaetes and typ- 
ical soft-bottom clams (Fig. 5b). Polychaete worms benefit from coarse-grained habitats with variable interstitial spaces in mytilid beds, which function as their main habitat on hard substrates (Tokeshi 1995). The addition of sand has also been found to markedly alter the fauna associated with coralline turfs (Airoldi 2003, Huff \& Jarett 2007). Overall, our study suggests that, although size is definitely important for species diversity up to a certain threshold, the 'patch quality', here defined as the presence/absence of additional structural components in mussel beds, might play a greater role in species diversity, composition and abundance. There is compelling evidence that patch quality, such as the presence of structural attributes, highly affects species distribution and abundance (e.g. Denoel \& Lehmann 2006, Lloyd 2008). It is likely that species dynamics are driven by multiple aspects of habitat quality, but, in order to gain a better understanding, more effort should be undertaken to appropriately measure the quality of a habitat (Mortelliti et al. 2010).

Blue mussel habitats provide excellent opportunities for determining how physical changes in a habitat's landscape, such as fragmentation or loss of structural components, may influence ecosystem structure and function. The present study clearly shows that both habitat quantity and quality have important effects on faunal assemblages in aquatic landscapes.

Acknowledgements. We express our gratitude to the staff at Tvärminne Zoological Station, who provided excellent facilities both in the field and laboratory. We also thank J. Erlandsson and 3 anonymous reviewers, whose comments greatly benefited an earlier draft of this manuscript. This work would not have been possible without the research grants from Onni Talaan säätiö (M.K.), Victoriastiftelsen (M.K.), the Walter and Andrée de Nottbeck Foundation (A.A.) and the Academy of Finland (M.W., Project 126831). The work complies with the current laws of Finland.

\section{LITERATURE CITED}

Airoldi L (2003) The effects of sedimentation on rocky coast assemblages. Oceanogr Mar Biol Annu Rev 41:161-236

Anderson MJ (1998) Effects of patch size on colonization in estuaries: revisiting the species-area relationship. Oecologia 118:87-98

Anderson MJ (2001) A new method for non-parametric multivariate analysis of variance. Austral Ecol 26:32-46

> Anderson MJ, Willis TJ (2003) Canonical analysis of principal coordinates: a useful method of constrained ordination for ecology. Ecology 84:511-525

Arrhenius O (1921) Species and area. J Ecol 9:95-99

Bell SS, Brooks RA, Robbins BD, Fonseca MS, Hall MO (2001) Faunal response to fragmentation in seagrass habitats: implications for seagrass conservation. Biol Conserv 100: 115-123

Bevers M, Flather CH (1999) Numerically exploring habitat fragmentation effects on populations using cell-based coupled map lattices. Theor Popul Biol 55:61-76
Bick A, Zettler ML (1994) The distribution of hydrobiids and the effects of sediment characteristics on the population dynamics of Hydrobia ventrosa in a coastal region of the southern Baltic. Int Rev Hydrobiol 79:325-336

Bologna PAX, Heck KL Jr (2000) Impacts of seagrass habitat architecture on bivalve settlement. Estuaries 23:449-457

> Boström C, Jackson EL, Simenstad CA (2006) Seagrass landscapes and their effects on associated fauna: a review. Estuar Coast Shelf Sci 68:383-403

Bowden DA, Rowden AA, Attrill MJ (2001) Effect of patch size and in-patch location on the infaunal macroinvertebrate assemblages of Zostera marina seagrass beds. J Exp Mar Biol Ecol 259:133-154

Coco G, Thrush SF, Green MO, Hewitt JE (2006) Feedbacks between bivalve density, flow, and suspended sediment concentration on patch stable states. Ecology 87:2862-2870

Coleman BD (1981) On random placement and species-area relations. Math Biosci 54:191-215

Commito JA, Rusignuolo BR (2000) Structural complexity in mussel beds: the fractal geometry of surface topography. J Exp Mar Biol Ecol 255:133-152

> Connor EF, McCoy ED (1979) The statistics and biology of the species-area relationship. Am Nat 113:791-833

Coull BC, Wells JB (1983) Refuges from fish predation: experiments with phytal meiofauna from the New Zealand rocky intertidal. Ecology 64:1599-1609

> Dayton PK (1971) Competition, disturbance, and community organization: the provision and subsequent utilization of space in a rocky intertidal community. Ecol Monogr 41: 351-389

> Denoel M, Lehmann A (2006) Multi-scale effect of landscape processes and habitat quality on newt abundance: implications for conservation. Biol Conserv 130:495-504

Diamond JM, May RM (1976) Island biogeography and the design of natural reserves. In: May RM (ed) Theoretical ecology: principles and applications. Blackwell Scientific, Oxford, p 163-186

> Erlandsson J, McQuaid CD, Kostylev VE (2005) Contrasting spatial heterogeneity of sessile organisms within mussel (Perna perna L.) beds in relation to topographic variability. J Exp Mar Biol Ecol 314:79-97

Fonseca MS, Meyer DL, Hall MO (1996) Development of planted seagrass beds in Tampa Bay, Florida, USA. II. Faunal components. Mar Ecol Prog Ser 132:141-156

Gaston KJ, Matter SF (2002) Individuals-area relationships comment. Ecology 83:288-293

Gotceitas V, Colgan P (1989) Predator foraging success and habitat complexity: quantitative test of the threshold hypothesis. Oecologia 80:158-166

Grafen A, Hails R (2002) Modern statistics for the life sciences - learn how to analyse your experiments. Oxford University Press Inc., New York, NY

Hamazaki T (1996) Effects of patch shape on the number of organisms. Landscape Ecol 11:299-306

Huff TM, Jarett JK (2007) Sand addition alters the invertebrate community of intertidal coralline turf. Mar Ecol Prog Ser 345:75-82

Irlandi EA, Ambrose WG Jr, Orlando BA (1995) Landscape ecology and the marine environment: how spatial configuration of seagrass habitat influences growth and survival of the bay scallop. Oikos 72:307-313

> Jelbart JE, Ross PM, Connolly RM (2006) Edge effects and patch size in seagrass landscapes: an experimental test using fish. Mar Ecol Prog Ser 319:93-102

Jones CG, Lawton JH, Shachak M (1997) Positive and negative effects of organisms as physical ecosystem engineers. Ecology 78:1946-1957 
Kautsky N, Wallentinus I (1980) Nutrient release from a Baltic Mytilus-red algal community and its role in benthic and pelagic productivity. Ophelia Suppl 1:7-30

Kelaher BP (2003) Changes in habitat complexity negatively affect diverse gastropod assemblages in coralline algal turf. Oecologia 135:431-441

Koivisto ME, Westerbom M (2010) Habitat structure and complexity as determinants of biodiversity in blue mussel beds on sublittoral rocky shores. Mar Biol 157:1463-1474

Koivisto M, Westerbom M, Riihimäki A (2011) Successiondriven facilitation of macrofaunal communities in sublittoral blue mussel habitats. Mar Biol 158:945-954

Kostylev V (1996) Spatial heterogeneity and habitat complexity affecting marine littoral fauna. PhD thesis, Göteborg University

Kostylev V, Erlandsson J, Johannesson K (1997) Microdistribution of the polymorphic snail Littorina saxatilis (Olivi) in a patchy rocky shore habitat. Ophelia 47:1-12

Kostylev VE, Erlandsson J, Mak YM, Williams GA (2005) The relative importance of habitat complexity and surface area in assessing biodiversity: fractal application on rocky shores. Ecol Complex 2:272-286

Laihonen P, Furman ER (1986) The site of settlement indicates commensalism between blue mussel and its epibiont. Oecologia 71:38-40

Leber KM (1985) The influence of predatory decapods, refuge, and microhabitat selection on seagrass communities. Ecology 66:1951-1964

Lloyd H (2008) Influence of within-patch habitat quality on high-Andean Polylepis bird abundance. Ibis 150:735-745

MacArthur RH, Wilson EO (1967) The theory of island biogeography. Princeton University Press, Princeton, NJ

Main KL (1987) Predator avoidance in seagrass meadows: prey behavior, microhabitat selection, and cryptic coloration. Ecology 68:170-180

Mortelliti A, Amori A, Boitani L (2010) The role of habitat quality in fragmented landscapes: a conceptual overview and prospectus for future research. Oecologia 163:535-547

Neigel JE (2003) Species-area relationships and marine conservation. Ecol Appl 13:138-145

Norkko J, Bonsdorff E, Norkko A (2000) Drifting algal mats as an alternative habitat for benthic invertebrates: species specific responses to a transient resource. J Exp Mar Biol Ecol 248:79-104

Norling P, Kautsky N (2007) Structural and functional effects of Mytilus edulis on diversity of associated species and ecosystem functioning. Mar Ecol Prog Ser 351:163-175

Norling P, Kautsky N (2008) Patches of the mussel Mytilus sp.

Editorial responsibility: Riccardo Cattaneo-Vietti, Genova, Italy are islands of high biodiversity in subtidal sediment habitats in the Baltic Sea. Aquat Biol 4:75-87

O'Connor NE, Crowe TP (2007) Biodiversity among mussels: separating the influence of sizes of mussels from the ages of patches. J Mar Biol Assoc UK 87:551-557

> Palomo MG, People J, Chapman MG, Underwood AJ (2007) Separating the effects of physical and biological aspects of mussel beds on their associated assemblages. Mar Ecol Prog Ser 344:131-142

Ragnarsson SA, Raffaelli D (1999) Effects of the mussel Mytilus edulis L. on the invertebrate fauna of sediments. J Exp Mar Biol Ecol 241:31-43

Saura S, Carballal P (2004) Discrimination of native and exotic forest patterns through shape irregularity indices: an analysis in the landscapes of Galicia, Spain. Landscape Ecol 19:647-662

Scheiner SM (2003) Six types of species-area curves. Glob Ecol Biogeogr 12:441-447

Svane I, Setyobudiandi I (1996) Diversity of associated fauna in beds of the blue mussel Mytilus edulis L.: effects of location, patch size, and position within a patch. Ophelia 45: $39-53$

Tanner JE (2003) Patch shape and orientation influences on seagrass epifauna are mediated by dispersal abilities. Oikos 100:517-524

Tews J, Brose U, Grimm V, Tielbörger K, Wichmann MC, Schwager M, Jeltsch F (2004) Animal species diversity driven by habitat heterogeneity/diversity: the importance of keystone structures. J Biogeogr 31:79-92

Tokeshi M (1995) Polychaete abundance and dispersion patterns in mussel beds: a non-trivial 'infaunal' assemblage on a Pacific South African American rocky shore. Mar Ecol Prog Ser 125:137-147

Tsuchiya M, Nishihira M (1985) Islands of Mytilus as a habitat for small intertidal animals: effect of island size on community structure. Mar Ecol Prog Ser 25:71-81

Tsuchiya M, Nishihira M (1986) Islands of Mytilus edulis as a habitat for small intertidal animals: effect of Mytilus age structure on the species composition of the associated fauna and community organization. Mar Ecol Prog Ser 31: 171-178

Westerbom M, Kilpi M, Mustonen O (2002) Blue mussels, Mytilus edulis, at the edge of the range: population structure, growth and biomass along a salinity gradient in the north-eastern Baltic Sea. Mar Biol 140:991-999

Witman JD (1985) Refuges, biological disturbance and rocky subtidal community structure in New England. Ecol Monogr 55:421-445

Submitted: December 1, 2010; Accepted: March 19, 2011 Proofs received from author(s): May 18, 2011 